\title{
Análise da relação de indicadores físico-químicos do lixiviado gerado em um aterro sanitário no Semiárido Brasileiro
}

\author{
Libânia da Silva Ribeiro ${ }^{1 *}$, Naiara Angelo Gomes ${ }^{1}$, Márbara Vilar de Araujo Almeida ${ }^{1}$, William de \\ Paiva $^{2}$
}

RESUMO: A degradação dos Resíduos Sólidos Urbanos (RSU) em aterros sanitários ocorre por meio de processos físicoquímicos e biológicos resultando na produção de líquidos lixiviados, que em função da variabilidade e heterogeneidade em sua composição podem ocasionar diferentes impactos à saúde pública e ao meio ambiente. Portanto, esse trabalho tem como objetivo caracterizar o lixiviado gerado no aterro sanitário instalado em Campina Grande, Paraíba, por meio da relação ácido-básico. A coleta do lixiviado in natura ocorreu durante os meses de maio de 2017 a janeiro de 2018 , na Lagoa de Tratamento de Lixiviado (LTL) que é responsável pela recepção da contribuição de todo efluente gerado no aterro. O lixiviado, após coletado, foi armazenado e encaminhado para o Laboratório de Geotecnia Ambiental onde foi caracterizado por meio da relação dos indicadores físico-químicos ( $\mathrm{pH}$, ácidos graxos voláteis e alcalinidade total). Os resultados demonstraram que o $\mathrm{pH}$ do lixiviado tendeu para valores entre a neutralidade e a basicidade, os ácidos graxos voláteis decaíram indicando que houve considerável degradação da matéria orgânica biodegradável, ainda houve acréscimos de alcalinidade total. Conclui-se que, por meio da relação do sistema ácido-básico, o lixiviado apresentou características de que a biodegradação dos resíduos sólidos urbanos ocorre de acordo com a digestão anaeróbia metanogênica, característico de pH básico, incrementos nos valores da alcalinidade e concentrações de ácidos graxos voláteis dentro da faixa usual para a idade do aterro.

Palavras-chave: efluentes; resíduos sólidos urbanos; sistema ácido-básico.

\section{Analysis of the relationship of physical-chemical indicators of the leachate generated in a landfill in the Brazilian Semiarid Region}

\begin{abstract}
The degradation of Urban Solid Waste (USW) in landfills occurs through physical-chemical and biological processes resulting in the production of leached liquids, which, due to the variability and heterogeneity in their composition, can cause different impacts on public health and the environment. Therefore, this work aims to characterize the leachate generated in the landfill installed in Campina Grande, Paraíba, through the acid-base system. The collection of in natura leachate took place from May 2017 to January 2018, in the Leachate Treatment Lagoon (LTL), which is responsible for receiving the contribution of all effluent generated in the landfill. The leachate, after being collected, was stored and sent to the Environmental Geotechnics Laboratory, where it was characterized through the relationship of physical-chemical indicators ( $\mathrm{pH}$, volatile fatty acids and total alkalinity). The results showed that the $\mathrm{pH}$ of the leachate tended to values between neutrality and basicity, the volatile fatty acids decreased, indicating that there was considerable degradation of biodegradable organic matter, there was still increases in total alkalinity. It is concluded that, through the relationship of the acid-base system, the leachate showed characteristics that the biodegradation of urban solid waste occurs according to the anaerobic methanogenic digestion, characteristic of basic $\mathrm{pH}$, increases in alkalinity values and acid concentrations volatile fatty acids within the usual range for the age of the landfill.
\end{abstract}

Keywords: effluents; urban solid waste; acid-base system.

\section{INTRODUÇÃO}

A geração desenfreada de Resíduos Sólidos Urbanos (RSU) que acontece pelo acelerado crescimento populacional, concentração das áreas urbanas, desenvolvimento industrial, mudanças de hábitos de consumo e desenvolvimento econômico, agrava ainda mais a problemática da gestão e do gerenciamento dos resíduos (GODECKE et al., 2012).

Devido as características de periculosidade que os resíduos apresentam, justifica-se que sua geração e o seu posterior abandono não podem ser exercidos aleatoriamente, sem nenhum tratamento, isso por envolver os mais diferentes impactos ambientais.
Uma alternativa para solucionar essa problemática constitui, segundo a Lei $n^{\circ} 12.305 / 10$, de um sistema de gerenciamento integrado que compreende em um conjunto de ações exercidas, direta ou indiretamente, nas etapas de coleta, transporte, transbordo, tratamento e destinação final ambientalmente adequada, como a coleta seletiva, reciclagem, compostagem e o uso de aterros sanitários (BRASIL, 2010).

O aterro sanitário de resíduos sólidos torna-se um sistema dinâmico e de alta complexidade por promover diferentes interações na massa de resíduos, que ocorre, principalmente, devido à composição 
química heterogênea desses materiais, que quando dispostos conjuntamente tendem a se degradar ao longo do tempo gerando subprodutos denominados de biogás e lixiviados, que se não tratados podem provocar danos à saúde pública e ao meio ambiente.

Diante deste contexto, os aterros sanitários representam um dos métodos utilizados para a disposição final e tratamento de resíduos sólidos urbanos. Sendo essa técnica uma das mais empregadas no mundo, devido a sua praticidade, baixo custo e viabilidade operacional, quando comparados a outras formas de tratamento (RENOU et al., 2008: HU; DU; LONG, 2017; LIMA et al., 2018).

O lixiviado, por sua vez, constitui de um líquido de coloração escura, alta concentração de matéria orgânica e compostos inorgânicos de difícil degradação, sendo considerado um dos maiores entraves em relação à operação de aterros sanitários (KATTEL et al., 2016). Em vista das características de contaminação, os lixiviados são potencialmente adversos à saúde pública e ao ambiente podendo contaminar o solo e as águas superficiais e subterrâneas, caso não sejam tratados de forma eficiente antes do seu lançamento (KULIKOWSKA; KLIMIUK, 2008; REGADÍO et al., 2012; MORAIS et al., 2020).

De acordo com Sá et al. (2012), o lixiviado de aterros sanitários são os efluentes resultantes da biodegradação dos RSU acrescidos da umidade natural dos resíduos, da água precipitada que infiltra e dos materiais dissolvidos que são carreados no processo de lixiviação. Além disso sua composição é variada ao longo da vida útil do aterro, pois suas características serão influenciadas diretamente pela idade do aterro sanitário, do grau de estabilização do RSU, das características do material aterrado e das condições meteorológicas.

$\mathrm{O}$ impacto produzido pelo lixiviado sobre o meio ambiente está diretamente relacionado com a sua fase de decomposição.
Desta forma, torna-se imprescindível monitorar a evolução dos parâmetros físico-químicos do lixiviado gerados em aterros sanitários, principalmente, a relação do sistema ácido/básico que é descrito basicamente pelo $\mathrm{pH}$, ácidos graxos voláteis e alcalinidade. Este sistema descreve as condições nas quais os fenômenos de degradação se processam, direcionando as reações no sentido da síntese ou dissociação de certos compostos, favorecendo ou não sua concentração no meio, regulando as formas e espécies químicas predominantes (CHERNICHARO, 2007).

O conhecimento de informações sobre este sistema e como se relacionam entre si é de fundamental importância, pois é a partir deste conhecimento que podem ser avaliados a decomposição dos resíduos ao longo do tempo e quais as características peculiares a cada fase de degradação após sua destinação final.

Assim o objetivo desse estudo consiste em caracterizar o lixiviado gerado a partir da degradação dos resíduos sólidos urbanos por meio da relação ácido-básico.

\section{MATERIAIS E MÉTODOS \\ Campo experimental}

Este trabalho foi desenvolvido no Aterro Sanitário construído em Campina Grande (ASCG), o qual está localizado a $10 \mathrm{~km}$ da área urbana desse município, sob coordenadas UTM 829172 e 9194834, que corresponde a Fazenda Logradouro II, distrito de Catolé de Boa Vista, município de Campina Grande, Paraíba (Figura 1).

Vale ressaltar que, esse empreendimento está inserido no semiárido brasileiro, região caracterizada por precipitação pluviométrica média anual inferior a $800 \mathrm{~mm}$; índice de aridez de até 0,5 e risco de seca, de um ano para o outro, maior que $60 \%$.

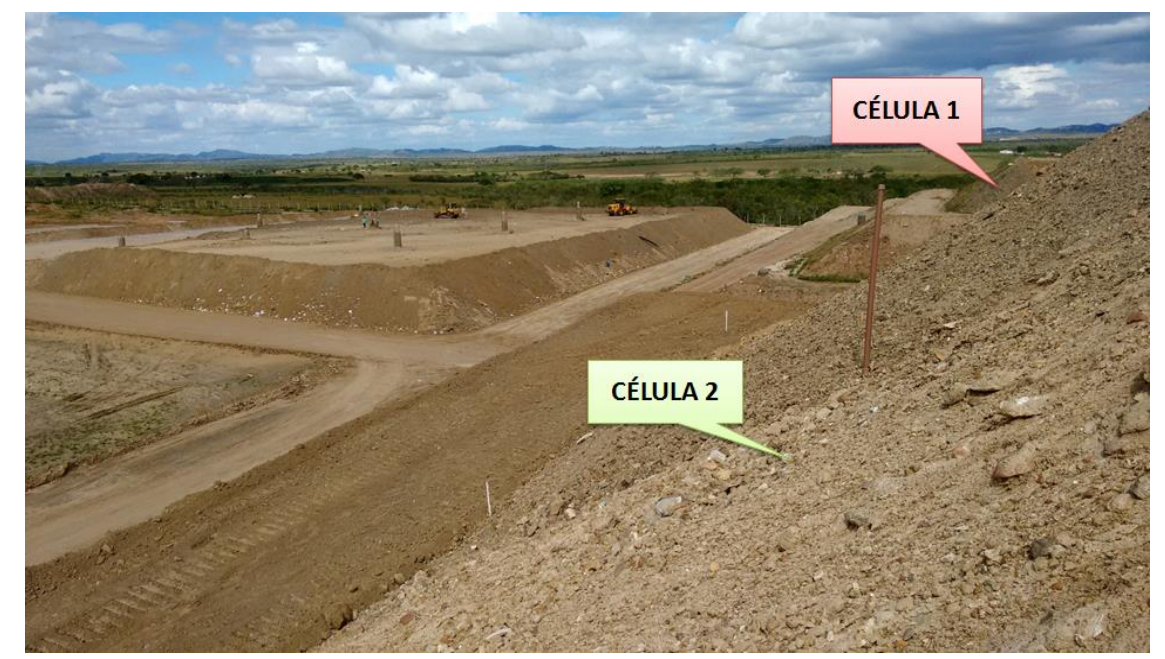

Figura 1- Aterro Sanitário em Campina Grande (ASCG).

Fonte: Arquivo da pesquisa (2019). 
O projeto do ASCG foi implantado em uma área total de 64 ha, sendo 40 ha destinados à disposição de RSU. Esse empreendimento foi dimensionado para uma capacidade de 350 tRSU.dia ${ }^{-1}$, resultando em uma vida útil de 25 anos (ECOTERRA, 2010).

Porém, o aterro, atualmente, recebe aproximadamente 600 tRSU.dia ${ }^{-1}$, sendo $97 \%$ desses resíduos provenientes do município de Campina Grande-PB.

Desde o início da operação, em julho de 2015, o ASCG recebe os resíduos sólidos urbanos dos municípios de Campina Grande, Puxinanã, Montadas, Boa Vista e Lagoa Seca. A partir de julho de 2017 passou a recepcionar os RSU dos municípios de Areia, Itatuba, Santa Cecília, Gado Bravo, Barra de Santana e Alcantil.

A geometria definida para o aterro sanitário contempla a instalação de 22 (vinte e duas) células de resíduos, das quais desde o início da operação do ASCG (julho de 2015) até a finalização deste estudo (janeiro de 2018), foram encerradas 3 (três) células de resíduos sólidos urbanos e, uma quarta célula encontra-se em operação.

As células do ASCG apresentam as dimensões aproximadas de área de base de $100 \times 100 \mathrm{~m}$, altura máxima de $20 \mathrm{~m}$, executadas a cada $5 \mathrm{~m}$, taludes com inclinação de 1:2 e bermas intermediárias de $6 \mathrm{~m}$ de largura. Essas células possuem um sistema de impermeabilização de base e cobertura, cujo intuito é evitar a lixiviação e infiltração de poluentes e contaminantes prejudiciais à saúde e ao meio ambiente.

\section{Monitoramento do lixiviado}

As amostras de lixiviado foram coletados na Lagoa de Tratamento de Lixiviado (LTL), conforme apresentadas na Figura 2 armazenados e preservados, segundo as orientações da CETESB (2011), e em seguida encaminhados para o Laboratório de Geotecnia Ambiental (LGA), pertencente ao Departamento de Engenharia Civil da UFCG, para a realização de sua caracterização físico-química. Essa caracterização foi realizada por meio dos indicadores que expressam o sistema ácido-básico, a saber: $\mathrm{pH}$, ácidos graxos voláteis e alcalinidade total conforme o APHA/AWWA/WEF (2017).
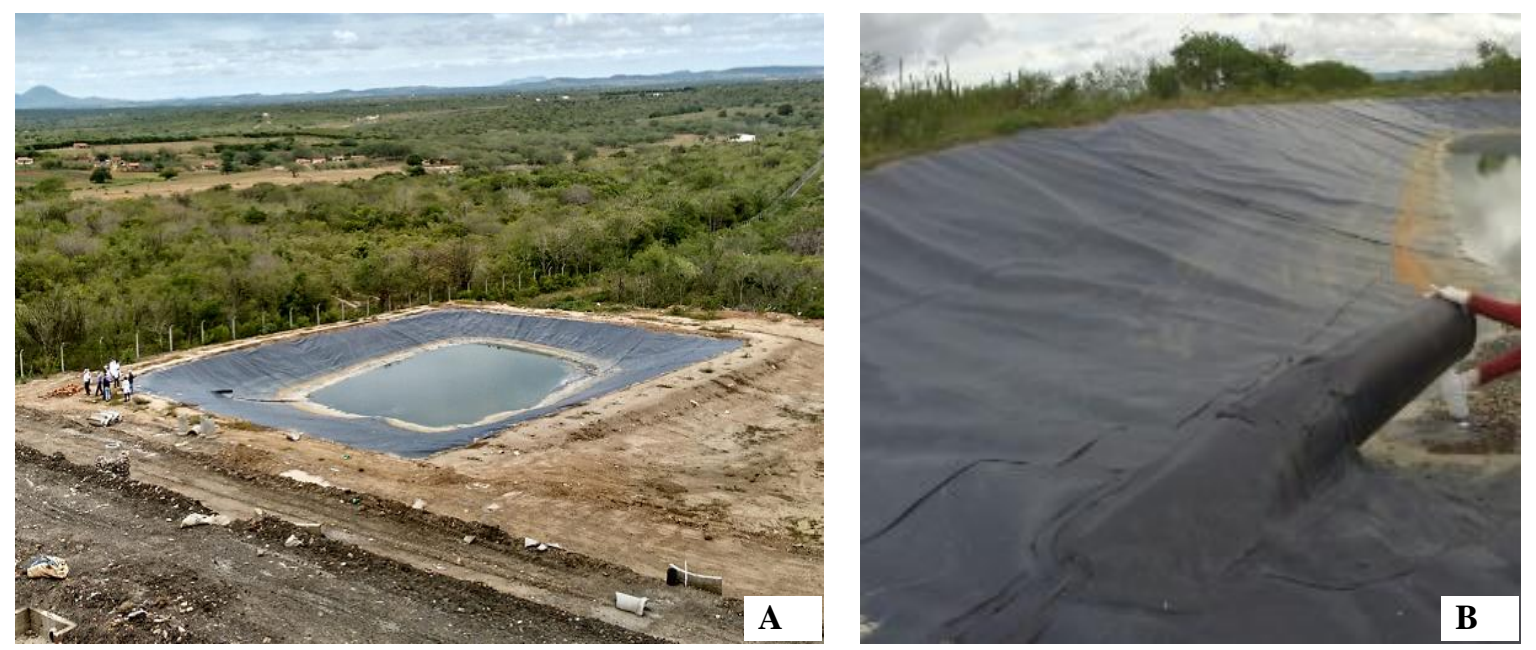

Figura 2- Lagoa de Tratamento de Lixiviado (LTL): A) Vista superior da LTL; B) Monitoramento da vazão Fonte: GGA/UFCG (2016)

\section{RESULTADOS E DISCUSSÃO \\ Parâmetros físico-químicos Potencial Hidrogeniônico (pH)}

$\mathrm{O}$ pH é um indicador importante para acompanhar a degradação dos resíduos sólidos urbanos, uma vez que, indica a evolução de sua estabilização, podendo, suas variações, acelerar ou inibir os processos biodegradativos, devido aos produtos formados a partir das várias fases de degradação da matéria orgânica (CASTILHOS et al., 2003).

A Figura 3 ilustra a variação do $\mathrm{pH}$ do lixiviado ao longo do tempo. 


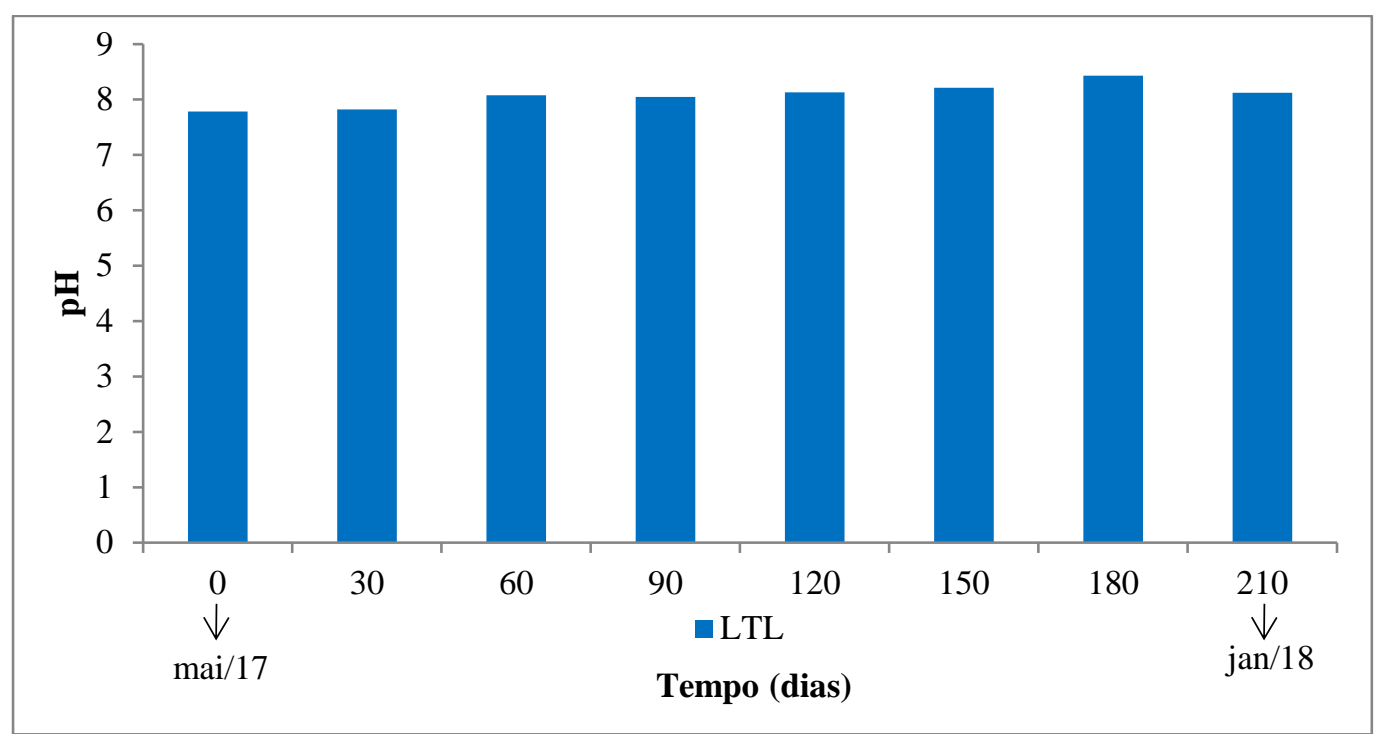

Figura 3- Evolução temporal do $\mathrm{pH}$ do lixiviado

Fonte: Acervo da pesquisa (2018)

Pode-se observar que o $\mathrm{pH}$ do lixiviado da LTL apresentou, inicialmente $(\mathrm{t}=0)$ características de $\mathrm{pH}$ básico, com valor próximo a 8,0 , ou seja acima da neutralidade. Esse dado indica que há uma acelerada degradação dos resíduos sólidos urbanos depositados no ASCG, sugerindo que essa degradação encontrase na fase metanogênica, visto que, de acordo com El Fadel et al.(2002), a evolução típica do processo de digestão anaeróbia para essa fase considera-se valores de $\mathrm{pH}$ acima da neutralidade.

De acordo com a Figura 3 o pH apresentou-se acima da neutralidade para todos os dias de monitoramento e variou entre uma faixa de 7,2 a 8,4. Esses valores observados sugere que o aumento do pH se dá pelo consumo dos ácidos graxos voláteis, por meio dos microrganismos anaeróbios, em especial, as bactérias metanogênicas, as quais apresentam taxa de crescimento mais lento e se instalam progressivamente induzindo assim, a elevação do $\mathrm{pH}$ por intermédio da catálise predominantemente, dos ácidos orgânicos (EGREJA FILHO, 1996; SOUTO e POVINELLI, 2007).

Comportamento semelhante aos dessa pesquisa foram observados por Ribeiro et al. (2016), em que avaliaram o comportamento da evolução do processo degradativo dos RSU depositado em um biorreator. Ácidos Graxos voláteis (AGV)

Os ácidos graxos voláteis tendem a com o tempo, bem como, sua biodegradação, isso se dá devido à presença de ácidos húmicos e fúlvicos, os quais são considerados de difícil degradação e permanecem por muito tempo presente na massa dos RSU ao longo da vida útil do aterro sanitário (CHRISTENSEN et al., 2001). Cabe ressaltar que, os ácidos fúlvicos é uma fração das substâncias húmicas que é solúvel em meio alcalino e ácido enquanto que, os ácidos húmicos é a fração solúvel em meio alcalino e insolúvel em meio ácido (KJELDSEN et al., 2002).

A Figura 4 apresenta os dados das concentrações dos ácidos graxos voláteis do lixiviado ao longo do tempo de monitoramento.

Essas variações ao longo do tempo de biodegradação, ocorre devido aos substratos gerados, pelas atividades dos microrganismos presentes, em cada fase assim, o $\mathrm{pH}$ do meio tende a aumentar devido ao hidrogênio dos grupos carboxílicos e fenólicos se dissociarem e se combinarem com a hidroxila do meio formando água.

Os dados verificados nesta pesquisa corroboram com os resultados obtidos no estudo de Ribeiro et al. (2016) para lixiviado de uma célula experimental com 3 anos de monitoramento.

Os valores obtidos também estão de acordo com outros trabalhos relacionados à simulação de aterros como o caso de Leite (2008), que apresentou valores acima de $1900 \mathrm{mgHac} . \mathrm{L}^{-1}$. 


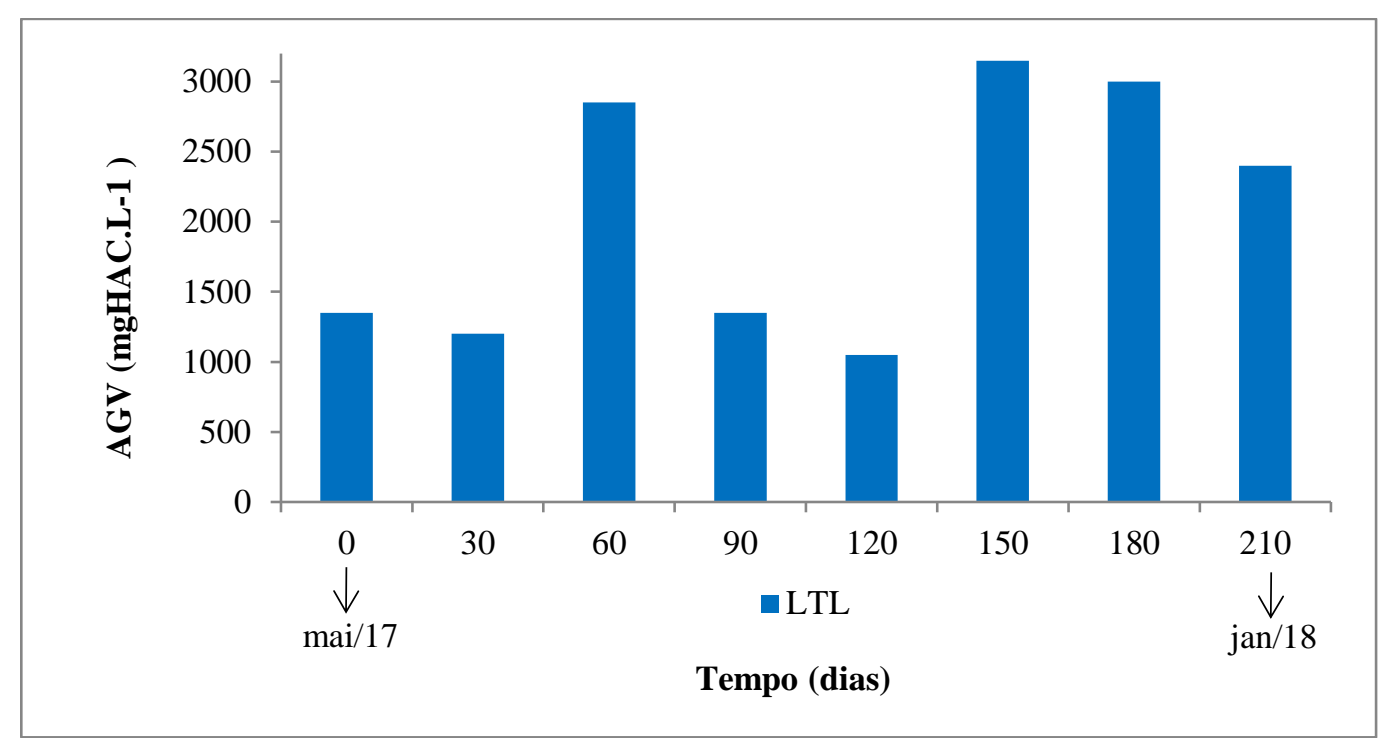

Figura 4- Ácidos graxos voláteis do lixiviado gerado no aterro sanitário.

Fonte:Acervo da pesquisa (2018).

\section{Alcalinidade Total (AT)}

Segundo METCALF e EDDY (2003) a alcalinidade é resultado da presença de hidróxilas $\left(\mathrm{OH}^{-}\right)$, carbonatos $\left(\mathrm{CO}_{3}{ }^{2-}\right)$, bicarbonatos $\left(\mathrm{HCO}^{3-}\right)$ e compostos nitrogenados. Outros componentes que contribuem com a alcalinidade são os boratos, silicatos, fosfatos e ácidos fracos, provenientes das proteínas, as quais liberam amônia, durante a hidrólise, e o acetato que é convertido em bicarbonato.

Assim, a alcalinidade é a medida da capacidade, dos íons presentes em um meio, de neutralizar ácidos agindo como um efeito tampão natural do meio. Desta forma, existe uma intrínseca relação entre o $\mathrm{pH}$, o teor de ácidos graxos voláteis e a alcalinidade total que determina o sistema ácido/base, devendo esta relação ser mantida dentro de limites para que exista um equilíbrio químico satisfatório entre os microrganismos, pois podem inibir ou não o processo biodegradativo dos resíduos sólidos.

$\mathrm{Na}$ Figura 5 estão ilustrados os dados da alcalinidade total ao longo do tempo de monitoramento.

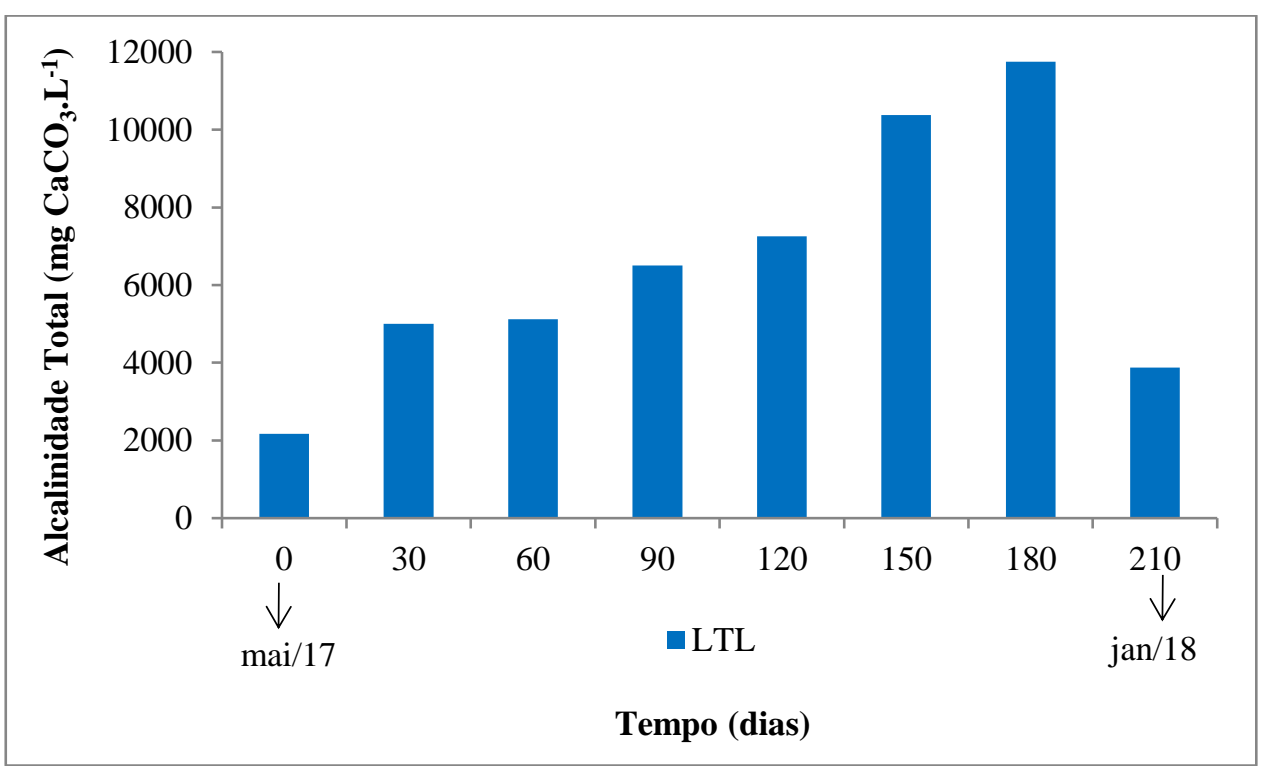

Figura 5- Alcalinidade total do lixiviado

Fonte: Acervo da pesquisa (2018)

De acordo com os dados apresentados na Figura 5, a alcalinidade total do lixiviado variou entre $2.166 \mathrm{e}$ $11.750 \mathrm{mgCaCO} 3 . \mathrm{L}^{-1}$, o que justifica os altos valores de $\mathrm{pH}$.
Ao longo do tempo de monitoramento, até $(\mathrm{t}=180)$ dias houve acréscimo de alcalinidade devido à degradação de certos compostos orgânicos como a conversão de ácidos graxos voláteis, proteínas e aminoácidos (CHERNICHARO, 2007). 
Andreotolla e Cannas (1992) cita que em aterros sanitários no Brasil, os valores de alcalinidade total podem variar de 300 a $11.500 \mathrm{mgCaCO}_{3} \cdot \mathrm{L}^{-1}$, já para Souto (2009) valores de alcalinidade variando entre 125 a $20.200 \mathrm{mgCaCO}_{3} \cdot \mathrm{L}^{-1}$, são típicos de aterros sanitários na fase metanogênica de degradação, o que corrobora com os dados apresentados nessa pesquisa.

De acordo com Contrera (2008), a alcalinidade total do lixiviado de aterros sanitários está intimamente ligada às concentrações de bicarbonato de amônio.

Desta forma, os altos valores de alcalinidade total obtidos nesse monitoramento, favorecem a neutralidade do meio e consequentemente, o desenvolvimento das bactérias arqueas metanogênicas, resultando assim, na geração de maiores concentrações de biogás.

\section{CONCLUSÕES}

Com o monitoramento dos parâmetros físicoquímicos, por meio do sistema ácido-básico do lixiviado gerado no Aterro Sanitário em Campina Grande (ASCG), sugere que a biodegradação dos resíduos sólidos urbanos, ocorre de acordo com a digestão anaeróbia da fase metanogênica, característico de $\mathrm{pH}$ básico, incrementos nos valores da alcalinidade e concentrações de ácidos graxos voláteis dentro da faixa usual para a idade do aterro.

\section{AGRADECIMENTO}

A CAPES, ao CNPq e a Universidade Federal de Campina Grande bem como a ECOSOLO GESTÃO DE RESÍDUOS LTDA.

\section{REFERENCIAS}

ANDREOTTOLA, G.; CANNAS, P. Chemical and Biological Characteristics of landfill Leachate. In: Chistensen, T.; Cossu, R.; Stegmann, R. Landfilling of Waste: Leachate. Great Britain, Chapman \& Hall, p. 65-88, 1992.

APHA, AWWA, WEF. Standard Methods for examination of water and wastewater. 23 nd ed. Washington: American Public Health Association, 2017, p.1360.ISBN 978-087553-013-0.

BRASIL. Lei $\mathrm{n}^{\circ} 12.305$, de 2 de agosto de 2010. Institui a Política Nacional de Resíduos Sólidos; altera a Lei no 9.605, de 12 de fevereiro de 1998; e dá outras providências.

CHRISTENSEN, T. et al. Biogeochemistry of Landfill Leachate Plumes. Applied Geochemistry, v. 16, p. $659-$ 718, 2001.

CETESB - COMPANHIA AMBIENTAL DO ESTADO DE SÃO PAULO. Guia de Coleta e Preservação de Amostras de Água. São Paulo: CETESB; Brasília: ANA, 2011, 326p.
CASTILHOS JR.A.B. Resíduos sólidos urbanos: Aterro sustentável para municípios de pequeno porte. Projeto PROSAB- RIMA, ABES. Rio de Janeiro, p. 294, 2003. ISBN 85-86552-70-4.

CHERNICHARO, C. A. L. Princípios do tratamento biológico de águas residuárias: reatores anaeróbios. 2.ed. Belo Horizonte: DESA-UFMG, v.5, 379p. 2007.

CHRISTENSEN, T.H.; BJERG, P.P.L.; JENSEN, D.L.; J.B.; CHRISTENSEN, A.; BAUM, A.; ALBRECHTSEN, H-J.; HERON G. Biochemistry of landfill leachate plumes. Applied Geochemistry. v.16, p. 659-718, 2001.

CONTRERA, R.C. Estudo da tratabilidade de lixiviados de aterros sanitários em sistema de reatores anaeróbio e aeróbio operados em bateladas sequenciais e em um filtro biológicos anaeróbio contínuo de fluxo ascendente. 2008. 789f. Tese (Doutorado em Hidráulica e Saneamento) Programa de Pós- Graduação de Engenharia de São Carlos, Universidade de São Paulo - SP.

ECOTERRA AMBIENTAL. Projeto de implantação de um aterro sanitário para resíduos sólidos no municipio de Campina Grande - PB: Estudo de Impacto Ambiental/ Relatório de Impacto Ambiental (EIA/RIMA). 2010.

EGREJA FILHO, F. B. Relatório de atividades de consultoria junto à superintendência de limpeza urbana de Belo Horizonte. Belo Horizonte: CODEPRO, 1996.

El FADEL, M.; DOUSEID, E.; CHAHINE, W.; ALAYLIC, B. Factors influencing solid waste generation and management. Waste Management. v.22, p. 269- 276, 2002.

FUENTES M, SCENNA NJ, AGUIRRE PA, MUSSATI MC. Application of two anaerobic digestion models to biofilm systems. Biochem Eng J. 38:259-269, 2008.

GODECKE, M. V.; NAIME, R.H.; FIGUEIREDO, J.A.S. O consumismo e a Geração de Resíduos Sólidos Urbanos no Brasil. Revista Eletrônica em Gestão, Educação e Tecnologia Ambiental, v.8, nº 8, p. 1700-1712, 2012.

HU, L.; DU, Y.; LONG, Y. Relationship between H2S emissions and the migration of sulfur-containing compounds in landfill sites. Ecological Engineering, v. 106, p. 17-23, 2017.

KATTEL, E.; TRAPIDO, M.; DULOVA, N. Treatment of landfill leachate by continuously reused ferricoxyhydroxide sludge-activated hydrogen peroxide. Chemical Engineering Journal, v. 304, n. 2, p. 646-654, 2016.

KJELDSEN, P.; BARLAZ, M. A.; ROOKER, A.P.; BAUN, A.; LEDIN, A.; CHRISTENSEN, T. Present and long-term composition of MSW landfill leachate: A Review. Environmental Science and Technology. V. 32, (4), p. 297-336, 2002. 
KULIKOWSKA, D.; KLIMIUK, E. The effect of landfill age on municipal leachate composition. Bioresource Technology, v. 99, n. 13, p. 5981- 5985, 2008.

LEITE, H. E. A. S. Estudo do comportamento de aterros de RSU em um bioreator em escala experimental na cidade de Campina Grande -PB. Dissertação de mestrado. Universidade Federal de Campina Grande, Campina Grande, PB, 218p. 2008.

LIMA, R. M. et al. Spatially distributed potential of landfill biogas production and electric power generation in Brazil. Waste Management, New York, v. 74, p. 323-334, 2018.

METCALF, L.; EDDY, Inc. Wastewater Engineering Treatment and Reuse. $4^{\mathrm{a}}$ edição. McGraw-Hill. 1819 p. 2003. ISBN 9780070418783.

MORAIS, M.; NASCIMENTO M. C. D.; MENEZES F. C.; SANTANA. M. R.; SILVA R. F.; SILVA T. O.; MAIA C.; PIMPÃO C. H. Análise Físico-Química e Microbiológica do Lixiviado do Aterro Sanitário de Rio Branco-AC. South American Journal of Basic Education, Technical and Technological, 7(1), 282-292, 2020 .

REGADÍO, M. et al. Pollution profiles and physicochemical parameters in old uncontrolled landfills. Waste Management (New York, N.Y.), v. 32, n. 3, p. 482-497, 2012.
REINHART, D. R. \& GROSH, C. J. (1998) Analysis of Florida MSW landfill leachate quality. Florida Center for Solid and Hazardous Management. Gainesville, FL, USA.

RENOU, S.; GIVAUDAN, J.G.; POULAIN, S.; DIRASSOUYAN, F.; MOULIN, P. Landfill leachate treatment: review and opportunity. Journal of Hazardous Materials, v. 150, n. 3, p. 468-493, 2008.

RIBEIRO, L.S.; SILVA, A.S.; ALVES, F. S.; MELO, M.C.; PAIVA, W.; MONTEIRO, V.D.E. Monitoramento físico-químicos de um biorreator com resíduos sólidos urbanos em escala piloto na cidade de Campina Grande (PB). Engenharia Sanitária e Ambiental (Online), v. 21, p.1-9, 2016.

SÁ, L. F.; JUCÁ, F. T.; SOBRINHO, M. A. M. Tratamento do lixiviado de aterro sanitário usando destilador solar. Revista Ambiente \& Água, v.07, n.1, 2012.

SOUTO, G.D.B. Lixiviado de Aterros Sanitários Brasileiros - estudo de remoção do nitrogênio amoniacal por processo de arraste com ar ("stripping"). 2009. 371 f. Tese (Doutorado em Engenharia Hidráulica e Saneamento) - Escola de Engenharia de São Carlos, Universidade de São Paulo, São Carlos-SP, 2009.

SOUTO, G. B.; POVINELLI, J. Características do lixiviado de aterros sanitários no Brasil. In: $24^{\circ}$ Congresso Brasileiro de Engenharia Sanitária e Ambiental. Anais. ABES. Belo Horizonte, 2007. 